\title{
Safety Level of Damaged RoPax Ships - \\ Risk Modelling and Cost-Effectiveness Analysis
}

\section{Authors:}

- Dr Luis Guarin - Project Manager, Safety at Sea Ltd, Glasgow

- Dr Dimitris Konovessis - Senior Lecturer, School of Marine Science and Technology,

Newcastle University

- Professor Dracos Vassalos, Department of Naval Architecture and Marine Engineering, Universities of Glasgow and Strathclyde 


\begin{abstract}
This paper elaborates on results of a recent risk analysis study for RoPax vessels, carried out as part of the activities of the SAFEDOR Integrated Project, targeting possible improvements on safety levels following large scale flooding. The study is based on a comprehensive analysis of accident statistics for the period 1994-2004, through which a high-level risk model (in the form of event trees) is established. This is then used to determine the current safety level of RoPax vessels (in various risk metrics, such as individual risk, potential loss of life and on an F-N curve), reconfirming that even though safety levels are improving, risk is still "high in the ALARP region". In search of ways to further improve the situation possible risk control options are examined, by performing a sensitivity analysis on the effects of the Attained Index of Subdivision A onto the safety levels and by evaluating their cost-effectiveness.
\end{abstract}

\title{
KEYWORDS
}

Damaged RoPax ships; risk modelling; cost-effectiveness 


\section{INTRODUCTION}

The main consequences on a RoPax following an accident may be graceful sinking or capsize and/or fire which can result in great loss of life among the passengers and crew onboard. The focus of this paper is on the evaluation of potential risk control options relating to credible accident scenarios that may lead to large scale flooding, using a high-level risk model. The work has been performed in accordance with the IMO FSA Guidelines [IMO, 2002].

At IMO, regulations on subdivision and damage stability of RoPax ships (SOLAS Chapter II-1) have received considerable attention over the years. Currently, the global standard for damage stability of RoPax ships is the vessel to be able to sustain any two-compartment damage and also fulfilling a set of deterministic requirements known as SOLAS 90. This represents a significant improvement with the standards applicable at the beginning of 1990s. In North West Europe, an increased standard is applied for existing ships, known as the "Stockholm Agreement” or SOLAS 90+50, which requires either fulfillment of the deterministic standards of SOLAS 90 with an additional height of water on deck (maximum of $50 \mathrm{~cm}$ ), or the demonstration by means of model experiments that the vessel can survive in damaged conditions the sea state at the area of operation.

The IMO’s Sub-Committee on Subdivision, Load Lines and Fishing Vessel Safety (SLF) has developed a new set of probabilistic rules for all ship types for global application from 2009 onwards. These rules follow the approach developed at Resolution A.265 (IMO issued this resolution at 1974, as an alternative to the deterministic SOLAS damage stability requirements) and are mainly based on extensive research work carried out at the late 1990s / early 2000s as part of the activities of the EC-funded research project HARDER. 
Following background information on the risk acceptance criteria used and an overview of relevant accident statistics, the paper provides details of the high-level risk model developed, discusses potential risk control options and evaluates their risk reduction potential as well as their cost-effectiveness. On the basis of these considerations some recommendations on appropriate safety levels of RoPax ships are given.

\section{BACKGROUND INFORMATION}

\section{Risk Acceptance Criteria}

The following outlines the acceptance criteria used in this study for individual risk (passengers and crew members) and for societal risk.

Individual risk is usually expressed as the frequency of an individual fatality per year. MSC72/16 proposes criteria for individual risk for shipping operations at the same level as those used by the UK Health and Safety Executive. These criteria are reproduced below for passengers and crew members.

Boundary between negligible risk and the ALARP area

Maximum tolerable risk for passengers (risks below this limit should be made ALARP)

Maximum tolerable risk for crew members (risks below this limit should be made ALARP)
$10^{-6}$ per year

$10^{-4}$ per year

$10^{-3}$ per year

Societal risk acceptance criteria for RoPax ships are established in the SAFEDOR public deliverable D4.5.2 (Risk Acceptance Criteria), in accordance with to the approach presented in document MSC 72/16, i.e. based on the economic importance of RoPax shipping. These criteria are presented in Figure 1. 


\section{Accident Statistics}

A thorough casualty statistics analysis has been carried out, based on historical data for the period 1994-2004, obtained by the Lloyds Maritime Information Unit (LMIU) and on fleet statistics for the same period, obtained by Lloyds Register Fairplay (LRFP).

The LMIU casualty database includes 1,147 incidents for RoPax ships world-wide for the period 1994-2004. 42 of the incidents included in the database have occurred on RoPax ships of 100 to 1,000 GRT. These are excluded from the analysis due to the fact that these smaller ships are usually engaged on short crossings and passages and are often of an open-type configuration and hence are not representative for a generic risk analysis study on RoPax ships (typically of a closed-type configuration and with part of her trip exposed to weather).

54 incidents have happened during repairs or conventions, labour and other disputes, on vessels that were already laid-up or to be broken up (9 incidents for RoPax of 1,000 to 4,000 GRT range and 45 incidents for RoPax of 4,000 GRT and above). These incidents have also not been taken into account in the analysis. Finally, there were a further 3 incidents which are attributed as acts of terrorism (notably one explosion involving considerable number of fatalities), which have also not been taken into account in the analysis.

Table 1 contains an analysis of the LMIU RoPax casualty data for the period 1994-2004, for RoPax of 1,000 GRT and above. Casualty records held by LMIU classify incidents as serious and non-serious. An incident is considered as serious if it has involved a single or multiple fatalities, damage to the vessel that has interrupted her service or if the vessel has been lost. 
Figure 1 illustrates the F-N for RoPax based on world-wide operation for the period 1994-2006 (i.e. including the Al Salam Boccaccio 98 incident, which caught fire on 3 February 2006 resulting in 1,000 fatalities among the 1,300 people onboard). The figure also includes, for comparison purposes, the F-N line representing experience with fatal incidents in North West Europe during the period 1978-1994.

Comparison on the F-N curve of the potential loss of life of the period 1994-2006 worldwide with North West European experience for the period 1978-1994, demonstrates a considerable risk reduction, however, it also demonstrates that risk is still high at the ALARP region.

\section{RISK MODELLING}

Based on the results of a HAZID session purposely organised (SAFEDOR, 2006) and the analysis of available accident statistics, as presented in the foregoing and summarized in Table 1, five generic top events were selected for further analysis, namely:

\section{- Collision}

- Grounding (incidents classified by LMIU as “wrecked/stranded”)

- Impact (incidents classified by LMIU as “contact”)

- Other flooding (incidents classified by LMIU as "hull damage" and "foundered") - Fire / Explosion

The next step in risk modelling was to assess the expected consequences for each of the identified events. This was done using event trees, i.e. by constructing and quantifying a sufficient number of scenarios of potential outcomes. The event trees relevant to the work 
presented in this paper, namely event trees for collision, grounding, impact and flooding from other causes, are illustrated in Figures 2 to 5.

Assignment of branch probabilities in the event trees of Figures 2 to 5 was done using accident statistics for the period 1994-2004, results from past relevant research studies (such as the Joint North West European Project, DNV Technica, 1996, and the HARDER project) and, where necessary, expert judgment.

Table 2 provides a summary of the risk calculations carried out, whilst Figure 6 presents the F-N curve calculated by the risk model. Comparing Figure 1 (historical risk) with Figure 6 (risk as calculated by the risk model), it can be seen that the prediction offered by the risk model is conservative with regards to the historical risk corresponding to the period $1994-2004$, but certainly well below the historical risk of the period 1978 - 1994 for North West European waters. As such, it can be considered a reasonable and adequate basis for evaluating the cost-effectiveness of the RCOs examined.

\section{RISK CONTROL OPTIONS}

Improved damage stability and survivability after flooding to avoid rapid capsize relates to the ability to stay afloat and upright for as long as necessary to allow for recovery of the vessel, safe continuation of the voyage or safe return to port, assistance to the vessel, or ultimately to allow for safe and orderly abandonment of the vessel.

Stability deterioration due to a magnitude of causes and subsequent flooding to internal compartments, had led in the past to major loss of life on RoPax ships (MV Herald of Free Enteprise, MV Estonia, MV Jan Heveliusz, MV Express Samina, MV El Salam Bocaccio, 
among others). Hence damaged ship stability is one of the fundamental areas of safety legislation as it deals with mitigating the consequences of water ingress related flooding.

The capsize mechanism of RoPax ships or any other ships with large un-subdivided horizontal spaces near the damaged waterline is associated with accumulation of water on deck due to wave action (see for instance, Tagg and Tuzcu, 2002, and Pawlowski, 2004). The height of the water gradually increases until either a reasonably stable equilibrium level is reached where inflow is approximately equal to outflow for ships with sufficient reserve stability, or if stability is inadequate, the heeling moment of the water will cause the ship to capsize. On this basis, a number of measures are known to be beneficial for the stability of RoPax ships following water ingress. Among others, the following can be quoted from (Pawlowski, 2004):

- Fitting of buoyant spaces (additional reserve buoyancy) on the car deck or below the weather deck, as appropriate, along the ship sides. This would increase the $\mathrm{GZ}_{\max }$ and decrease the heeling level due to water accumulated on deck.

- Use of down-flooding arrangements which counteract the accumulation of water on the vehicle deck, and if properly designed, can largely reduce or even eliminate this phenomenon.

- Application of sheer of the deck and/or trim of the ship to limit the extent of water accumulation on deck by increasing water outflow; this is of importance for midship flooding cases, the most detrimental for residual stability.

For new RoPax designs, the above three measures can be effectively incorporated without greater difficulties, taking the form of a lifebelt around the ship’s sides, leading to designs of unprecedented high levels of survivability (Pawlowski, 1999). A good illustration of the above measures on a RoPax design can be found in a public report of the DESSO project where, the vessel was conceived with the philosophy of the ship functioning as "its own lifeboat". Among 
the measures introduced in this design, efficient cross-flooding arrangements (for achieving symmetric flooding and avoiding excessive heel) as well as enclosed watertight side casings for providing reserve buoyancy up to the first accommodation deck, can be accounted for.

As the results of risk analysis suggest, rapid capsize - as a consequence of various accident categories leading to various extents of flooding, is the main contributor to ship losses and the cause of a large number of fatalities. In this sense, during the concept design stages of a new ship project, in addition to 'conventional' (static stability) design methods for quantifying damage stability, the issue of verification of the survival time in cases of flooding would help to improve the survivability performance of the ship.

In relation to the above and for the purpose of the cost-effectiveness study, two high-level RCOs have been considered:

- $\quad$ RCO2a: relates to measures aimed at improving damage stability in a statutory sense only. The effectiveness of different measures is quantified on the basis of 'conventional' methods i.e. static stability calculations and it is expressed with the probabilistic Attained Index of Subdivision A. The explicit issue of the survival time is not directly addressed in Index A calculations, although the implicit $\boldsymbol{s}$ factor formulation encodes implicitly information on sea state as well as the time the vessel is expected to survive in specific damage conditions. It is expected that this RCO would lead to moderate increases of Index A, and that the associated costs are not major or significant.

- $\underline{\mathrm{RCO} 2 \mathrm{~b}}$ : relates to improved damage stability as above, but the issue of the survival time is also directly and explicitly addressed with a performance-based approach (model tests and/or numerical simulations). This will ensure that the problem of rapid capsize is addressed for all 
possible flooding scenarios and it is not limited to collision damages. It is assumed that this RCO would lead to moderate increases of Index A and that in addition, its implementation would also lead to reduce the probability of rapid capsize (as opposed to slow sinking) in those situations in which the vessel "does not remain afloat". This RCO is meant to achieve high levels of survivability in line with the concept of "casualty threshold" and safe return to port (Vassalos, 2007) therefore the marginal costs associated with RCO2b are expected to be much higher than with RCO2a.

The risk reduction potential of all measures associated with improved damage stability and survival time, can be evaluated by assessing the impact of all related measures on the branch probabilities of the event trees constituting the (high-level) risk model. Accordingly, the maximum risk reduction potential associated with $\mathrm{RCO} 2$ is $\Delta \mathrm{R}_{\max }=73 \%$ (of total PLL basis) and relates to all collisions, groundings, cases of impacts and flooding from other causes.

\section{RCO2a (improved capability to "stay afloat")}

All possibilities and specific design solutions associated with implementing RCO2a would lead to varying degrees of improved stability after flooding. This increased level can be quantified in terms of Index A (as defined in the newly adopted SOLAS 2009 Chapter II-1 regulations), and the improvements would positively impact the probability of "staying afloat" in all collision and flooding events defined in the risk model.

The Required Index of Subdivision R for the representative RoPax vessel adopted in this study is equal to $R=0.735$ and is a function of the subdivision length $\left(L_{s}\right)$ and the number of persons the vessel is certified to carry. In the risk model, an Index A of 0.78 (average value of a sample of 38 RoPax vessels) has been used for the calculation of the basis risk. Since A>R, then the vessel 
complies with the probabilistic rules, and the same value of Index A is adopted here for consistency.

According to the concept behind the probabilistic framework, if a ship attains an Index A value of 0.78 , it can be interpreted as meaning that in $78 \%$ of all potential collisions resulting in water ingress and flooding, the survival time would - theoretically at least - be 30 minutes $^{1}$ or more. This also means that the remaining $22 \%$ of the collisions, the time would be less than 30 minutes!

For a given damage case, the $\boldsymbol{s}$ factor formulation is assumed to reflect the percentage of cases the ship would survive for at least 30 minutes. Accordingly, if s=1.0, the mean survival time would tend to infinity, this is assuming of course that the current $s$ factor formulation reflects appropriately the conditional probability that the ship will not capsize in a given critical sea state. In this respect, the following comments are made with respect to the current $s$ factor formulation as adopted in the SOLAS 2009 rules:

- The positive impact of many design measures to improve damage stability may not be reflected in the resulting Index A value (for more details see Vassalos et al, 2006).

- $\quad$ Recent studies (Vassalos and Jasionowski, 2007) suggest that the $s$ factor formulation eventually adopted in the SOLAS 2009 rules is based on a regression of data corresponding to conventional cargo ships, which would tend to overestimate (not conservative!) the probability of survival of RoPax (low freeboard) ships.

Consequently, it is not known with certainty whether the $s$ factor formulation adequately reflects the true damage stability and the level of survivability of passengers ships, in particular of RoPax vessels.

\footnotetext{
${ }^{1}$ Duration of model tests on the basis of which the s factor formulation was derived (Tagg and Tuzcu, 2002)
} 
Notwithstanding the above, for the purpose of this study, it can be assumed that Index A is a measure of damage stability and as such, any design measure introduced to increase Index A value, would lead to a higher probability of “staying afloat”. Thus, a systematic increase from $\mathrm{A}=0.78$ (the basis level) up to $\mathrm{A}=0.99$ is considered for estimating the range of risk reduction implied by implementing RCO2a. The impact on the specific branches of the event tree (ET, the risk model) is as indicated in Table 3. The results of sensitivity of the risk level to different values of Index A, (i.e. to different levels of success in the implementation of these measures) are presented in Table 4.

As can be noted, for example, if the vessel attains an Index A of 0.90, the resulting reduction of the total Potential Loss of Life $(\Delta \mathrm{R})$ is estimated at 44\%; the breakdown into the considered accident categories is shown in Table 5 for the $A=0.90$ case. The resulting FN curve is illustrated in Figure 7. In the extreme case of $A=0.99$ the level of risk reduction of the total PLL in relation to the basis case can be as much as $\Delta \mathrm{R}=63 \%$.

\section{RCO2b (improved capability to "stay afloat longer")}

This RCO assumes that all measures implemented are much more effective in achieving the design goal of "stay afloat for longer"; it is expected that more effective measures can be designed if in addition to 'conventional' design verification methods based on static stability, state-of-the-art performance-based methods (numerical simulations) are utilised at early design stages for verification and systematic improvement of survivability performance not only for collision-related damages, but for a range of representative scenarios related to groundings, impact and other flooding scenarios. Modern performance-based methods are used for verification of structural strength, hull resistance, aerodynamic performance, evacuation, etc. 
There is no reason why modern survivability analyses should not be utilised to design and verify one of the key safety ship design goals (“stay upright and afloat”) for as long as necessary to recover the ship or eventually to allow for safe abandonment.

Obviously, the impact on survivability can also be expressed in terms of Index A, which is likely to be higher than that achieved in RCO2a, as there will be more cases for which the $\boldsymbol{s}$ factor is unity, hence survival time would tend to infinity. In addition to this, for all cases where the ship does not remain afloat, the proportion of 'slow sinking' to 'rapid capsize' is assumed also equal to the expected probability of survival (Index A). In this RCO the confidence in the "adequateness" of the $\boldsymbol{s}$ factor formulation implicit in Index A calculations is high.

The results of sensitivity of the risk level to different values of Index A, (i.e. to different levels of success in the implementation of these measures) are illustrated in Tables 6 and 7. As can be noted, for example, if the vessel attains an Index A of 0.95, the resulting reduction of the total Potential Loss of Life $(\Delta \mathrm{R})$ is estimated at $62 \%$; the breakdown into the considered accident categories is shown in Table 8 for the $A=0.95$ case. The resulting FN curve is illustrated in Figure 8.

\section{COST-EFFECTIVENESS ANALYSIS}

\section{Generic Model / Ship System}

For the purpose of evaluating the risk reduction potential $(\Delta \mathrm{R})$ and costs $(\Delta \mathrm{C})$ of the RCOs considered, a representative reference ship has been selected, the main parameters of which are presented in Table 7. The parameters of the reference ship correspond to a RoPax vessel with capacity for approximately 1,000 passengers and 100 crew, consistently with the assumptions made in the risk analysis study. 
All costs and benefits were depreciated to a Net Present Value (NPV) using a depreciation rate of 5\% and assuming an expected lifetime of 30 years for RoPax ships.

As the marginal costs are a function of the operational profile of the vessel, a specific operational profile was defined as summarised in Table 10, comprising three seasonal periods (winter, spring/autumn and summer), in line with the assumptions made in the risk model. Additional assumptions made include operation of 356 out of 365 days per year (with 99\% availability) and a reference trip of distance 300 nautical miles, travelled at average speed of 25 knots in 12 hours.

On the basis of the cost/revenue unit data presented in Table 11, the corresponding costearning profile is shown in Table 12. On the basis of these assumptions, the annual total revenue is estimated as $€ 18,440,426$ whilst the annual operating costs are $€ 17,108,000$ resulting in a net annual profit of $€ 1,322,426$ ( $€ 731$ per cabin and $€ 605$ per lane metre).

On the basis of these operating figures, indicative estimates of marginal costs associated with the various design measures implied by introducing RCO2a and RCO2b were made, as related to the extent of possible utilisation of the available volumes and deck areas and their effects on the layout and capacity of the ship. Tables 13 and 14 present the marginal costs taken into account for RCO2a and RCO2b, respectively.

\section{CAF Calculation}

The results of cost-effectiveness calculations (GCAF) for RCO2a are illustrated in Figure 9. For RCO2b, the results are illustrated in Figure 10; the figures show sensitivity of GCAF to different assumptions related to risk reduction and cost. Figures 9 and 10, in conjunction with Figures 7 and 8, indicate that if the Required Index A for the representative ship is increased from 0.78 to 
0.90, the measure is cost-effective if the total marginal cost associated with the stability upgrade is less than US\$9M and US\$11M for RCO2a and RCO2b, respectively (since for both cases, the associated CAF value is up to US\$3M). Experience from Stockholm Agreement stability upgrades indicate that such cost can be significantly lower than US\$9M.

\section{CONCLUSIONS}

On the basis of the work presented in this paper on potential measures aimed at improving damage stability and survivability, and assuming that damaged ship survivability is 'sufficiently' reflected by the attained subdivision index (A), then the required subdivision index (R) should be increased so that for the average size ferry (1,100 persons onboard), the R index is above 0.90 . When a ship attains an $A$ value of $A>0.90$, it would mean that more than $90 \%$ of potential collisions would result in survival time of 30 minutes or longer. A high A value ( $>0.90)$ would also imply that there would be a larger number of damage cases with s=1.0, which, for a given damage case, implies infinite mean survival time $(t \rightarrow \infty)$.

In relation to this conclusion, the following points are noteworthy:

- Although the current formulation of the required index $\mathrm{R}$ is a measure of safety in line with current expectations, it does not explicitly relate to risk; it has been established on the basis of the attained index from a sample of RoPax ships of SOLAS 90 standard; thus the R index may not reflect the level of safety to be expected in the foreseeable future. An attempt to relate $\mathrm{R}$ more directly to safety would require the use of risk in its derivation.

- The formulation of the $s$ factor should be urgently revisited for passenger ships, including RoPax ships, using relevant reference ships (RoPax) and utilising available performancebased methods. 
Finally, on the basis of cost-effectiveness considerations, it is expected that the CAF value associated with the introduction of measures to improve survivability in flooded conditions is going to be well below the current cost-effectiveness criterion (US\$3M), even for pessimistic assumptions of marginal costs. Hence it is strongly recommended that the required subdivision index R for RoPax vessels be increased to levels at least or above 0.90 .

\section{ACKNOWLEDMENTS}

The work reported in this paper has been carried out under the SAFEDOR Integrated Project IP516278, with partial funding from the European Commission. The opinions expressed are those of the authors and should not be construed to represent the views of the SAFEDOR partnership.

\section{REFERENCES}

DNV Technica (1996). “Safety Assessment of Passenger Ro-Ro Vessels”, Main Report (Document Number: REP-T09-003), Joint North West European Project, 28.10.1996.

IMO (2000). "Formal Safety Assessment: Decision Parameters including Risk Acceptance Criteria”, MSC72/16, Submitted by Norway.

IMO (2002). "Guidelines for Formal Safety Assessment (FSA) for use in the IMO rule-making process”, MSC/Circ.1023.

http://www.sspa.se/download/re/desso_brochure.pdf

Pawlowski M (1999). “Subdivision of RO/RO Ships for Enhanced Safety in the Damaged Condition”, Marine Technology, Vol 36, No. 4 Fall 1999, pp 194-202.

Pawlowski M (2004). “Subdivision and Damage Stability of Ships”, Euro-MTEC series, ISBN 83-919488-6-2, Gdanks 2004. 
SAFEDOR (2005). "Risk Evaluation Criteria”, SAFEDOR Deliverable D4.5.2.

SAFEDOR (2006). "HAZID for RoPax”, SAFEDOR Deliverable D4.2.1.

Tagg R, Tuzcu C (2002). “A Performance-based Assessment of the Survival of Damaged Ships Final Outcome of the EU Research Project HARDER”, Proceedings of the 6th International Ship Stability Workshop, Webb Institute, 2002.

Vassalos D, York A, Jasionowski A, Kanerva M, Scott A. (2006). "Design Implications of the New Harmonised Probabilistic Damage Stability Regulations”, Proceedings of the $9^{\text {th }}$ International Conference on Stability of Ships and Ocean Vehicles (2006).

Vassalos D, Jasionowski A (2007). “SOLAS 2009 - raising the alarm”, Proceedings of the $10^{\text {th }}$ International Conference on Stability of Ships and Ocean Vehicles (2007).

Vassalos D (2007). “Risk-Based Design: Passenger Ships”, SAFEDOR mid-term conference, RINA, May 2007. 


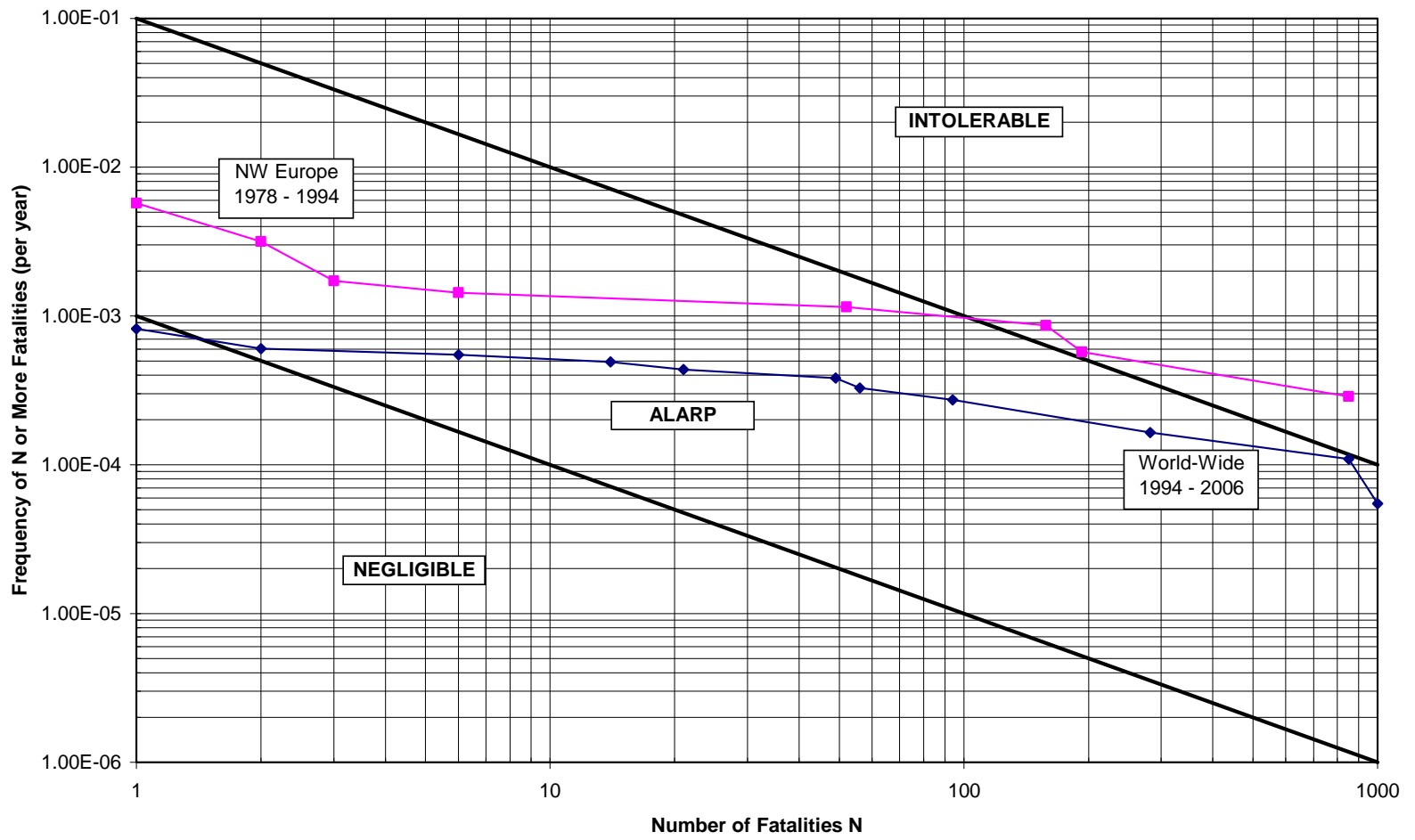

Fig. 1: RoPax F-N Curve (Historical Risk) 


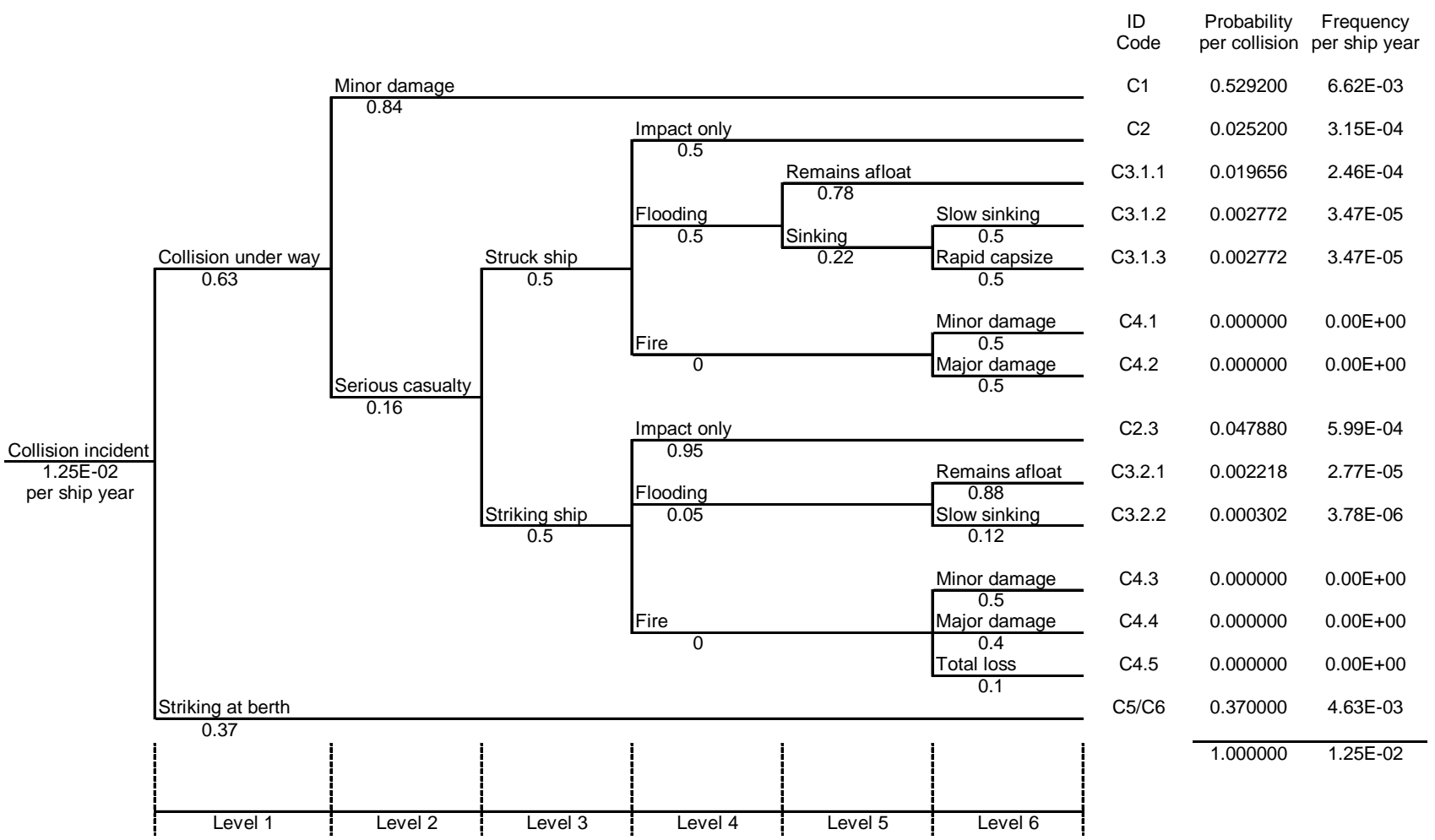

Fig. 2: Generic Collision Event Tree 


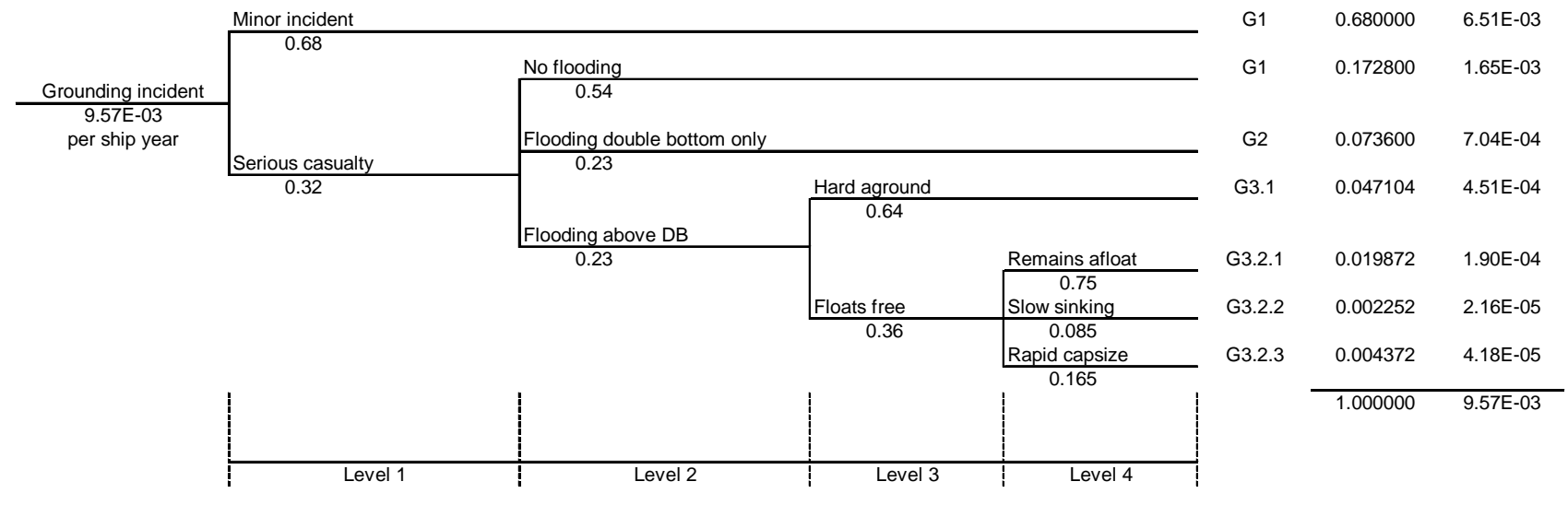

Fig. 3: Generic Grounding Event Tree 


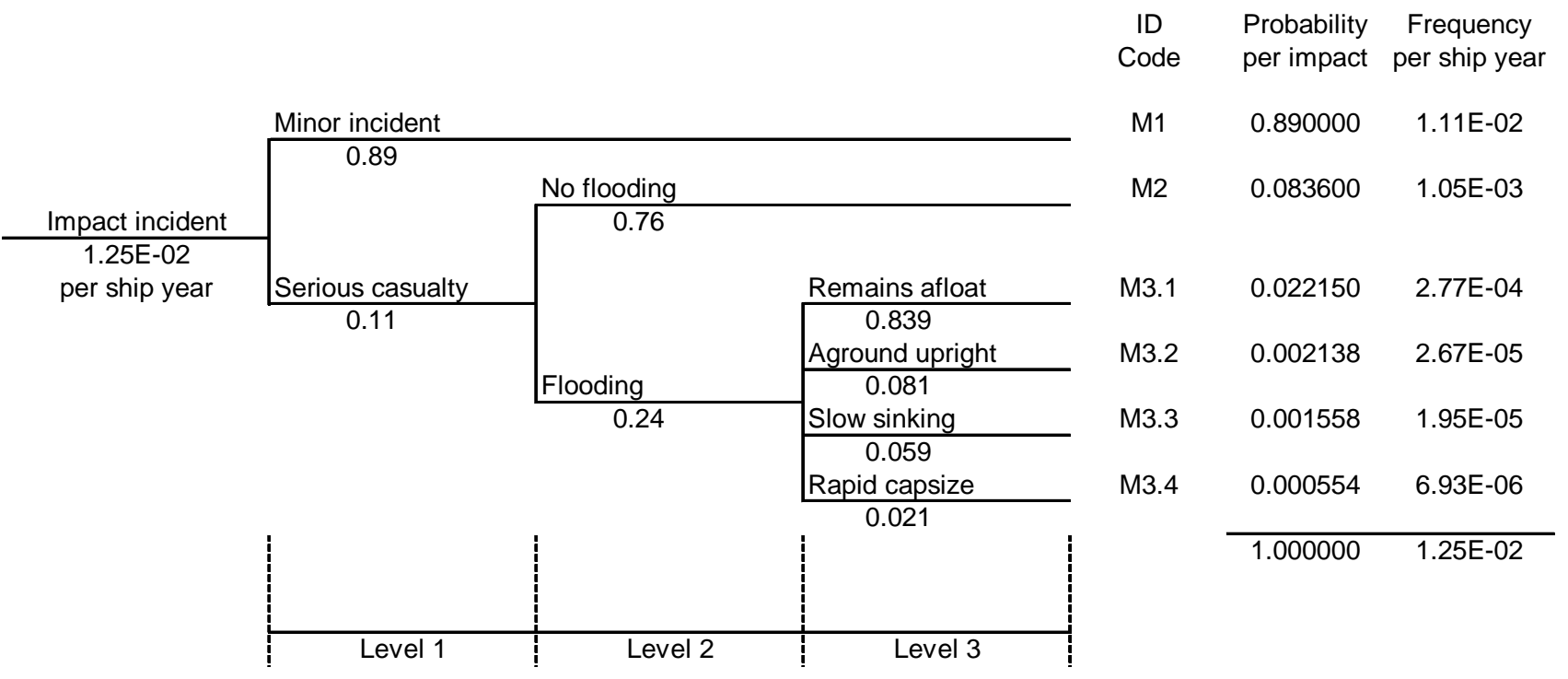

Fig. 4: Generic Impact Event Tree 


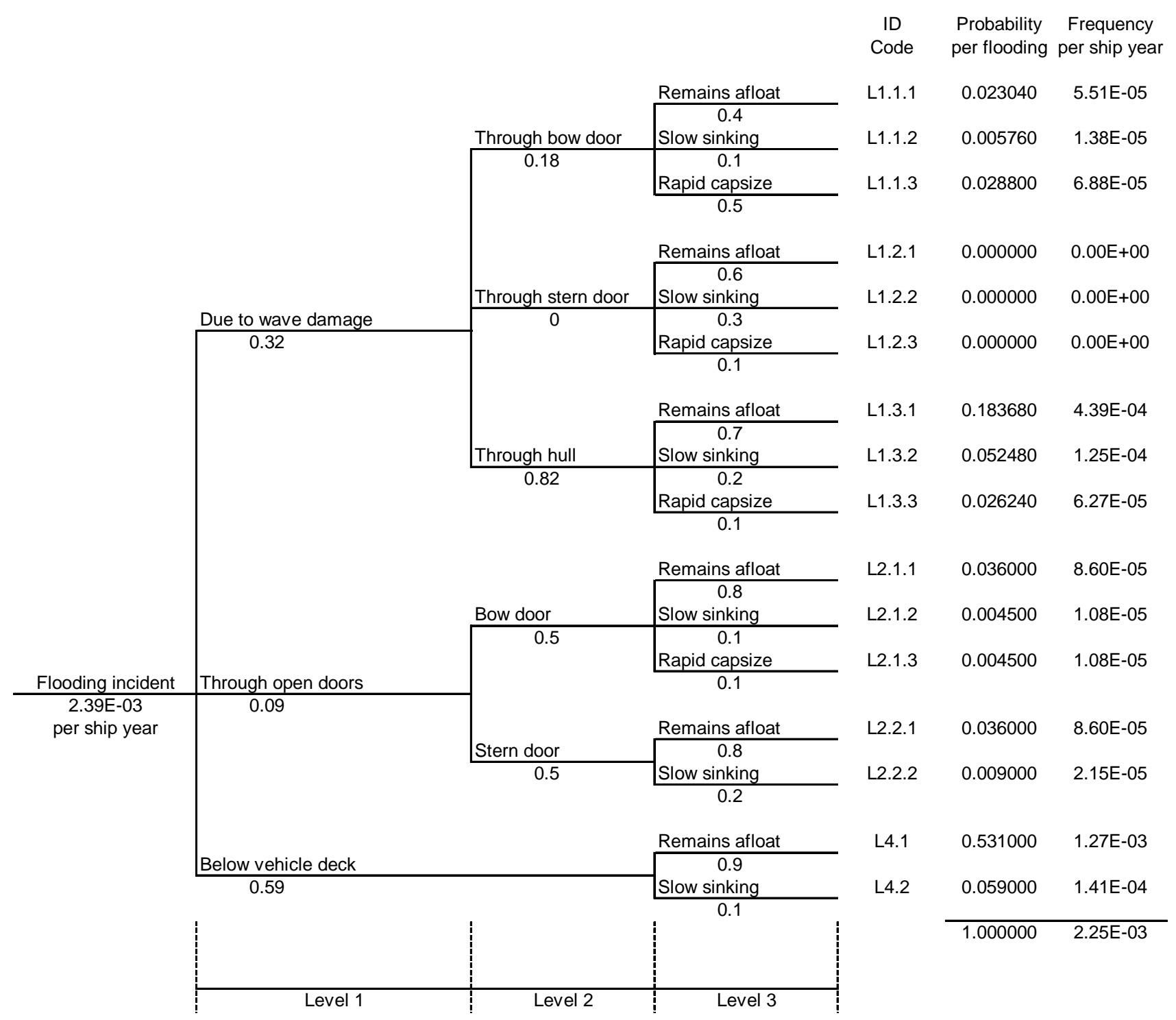

Fig. 5: Generic Flooding Event Tree 


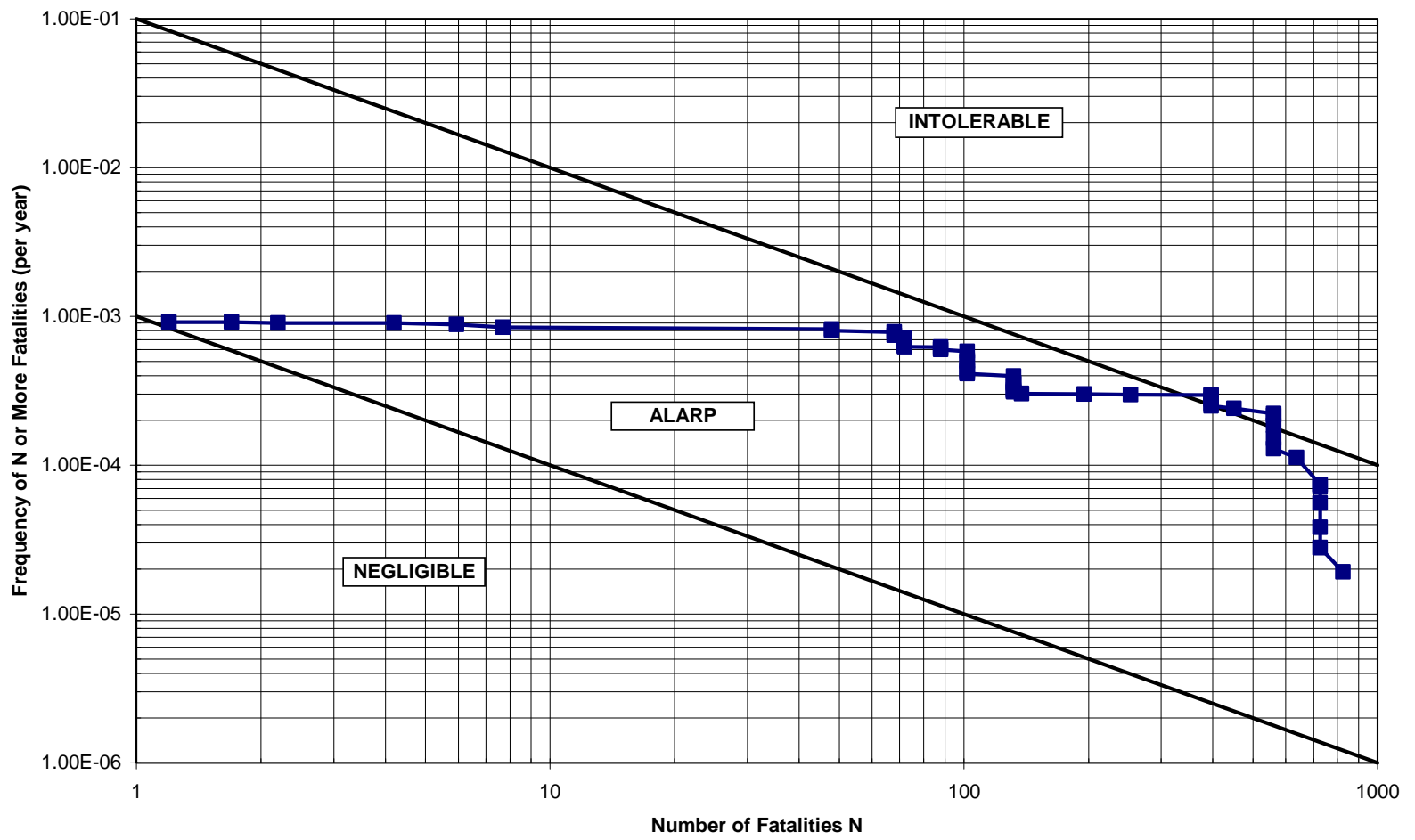

Fig. 6: RoPax F-N Curve (Risk Model) 
FN RoPax Vessels

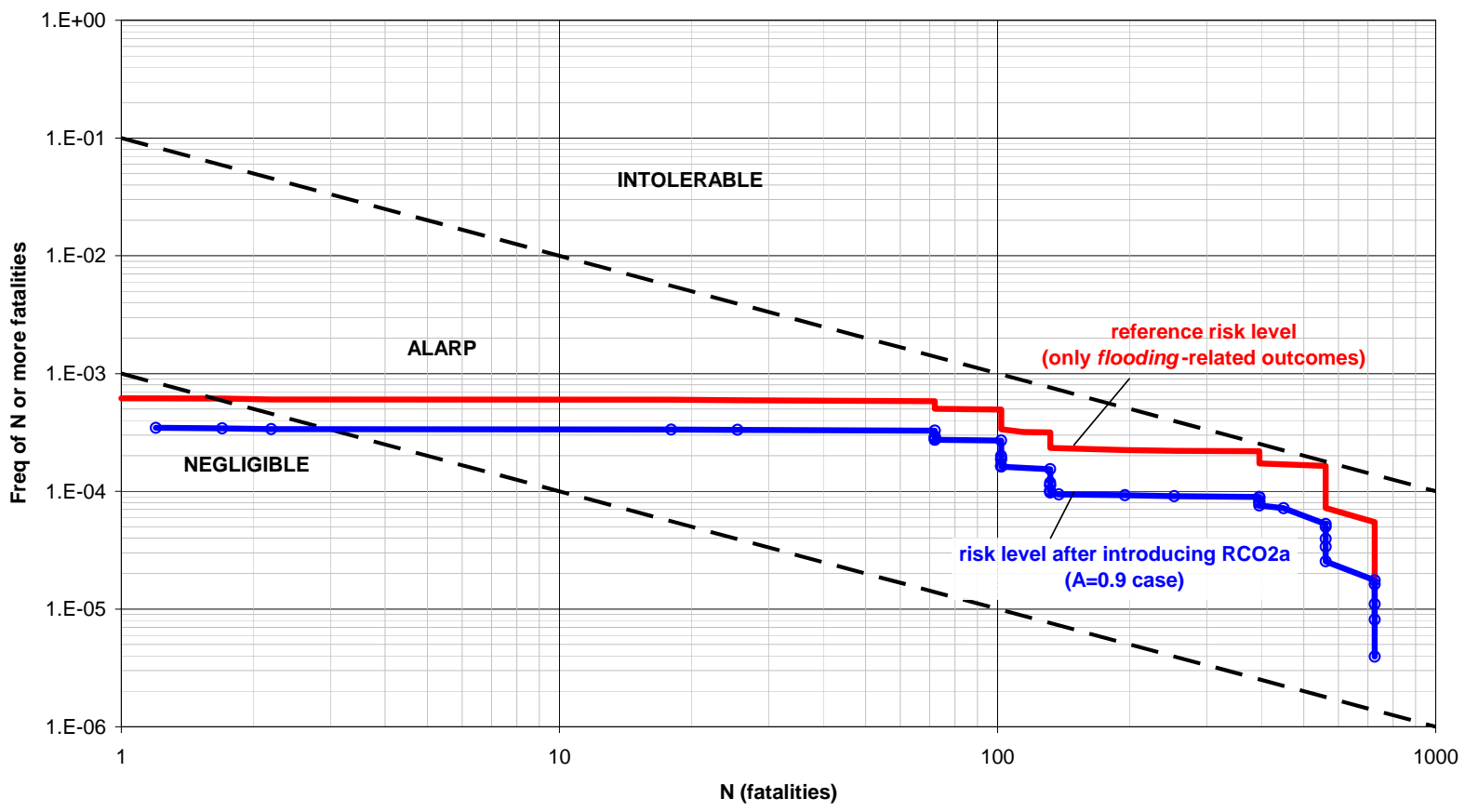

Fig. 7: Societal Risk Associated with Flooding-Related Outcomes - RCO2a (collision, grounding, impact and flooding accident categories included) 
FN RoPax Vessels

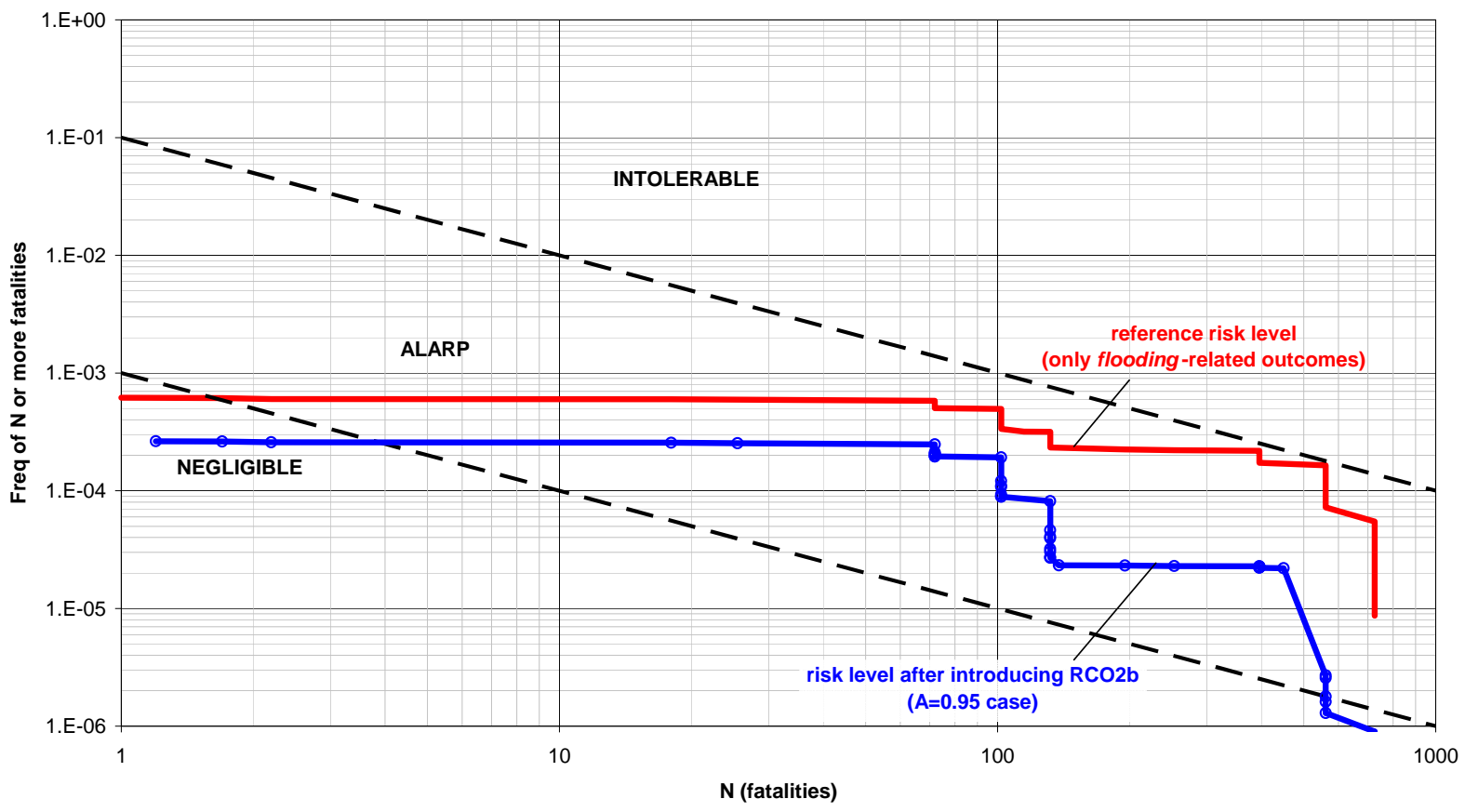

Fig. 8: Societal Risk Associated with Flooding-Related Outcomes - RCO2b (collision, grounding, impact and flooding accident categories included) 


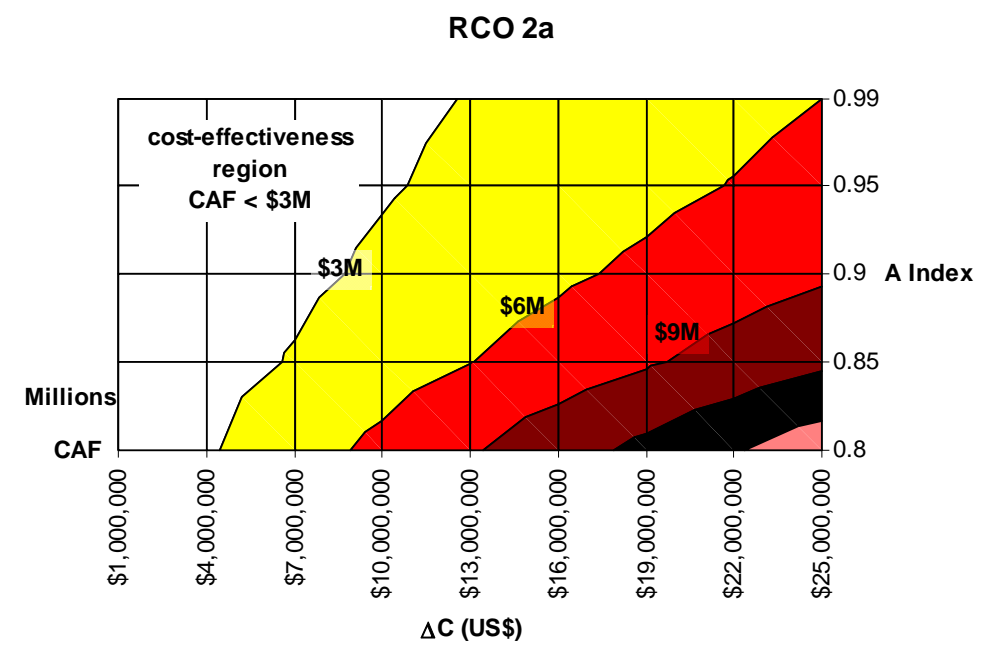

Fig. 9: GCAF sensitivity to Attained index A and cost implications RCO2a: measures improving damage stability ("stay afloat”) 
RCO 2b

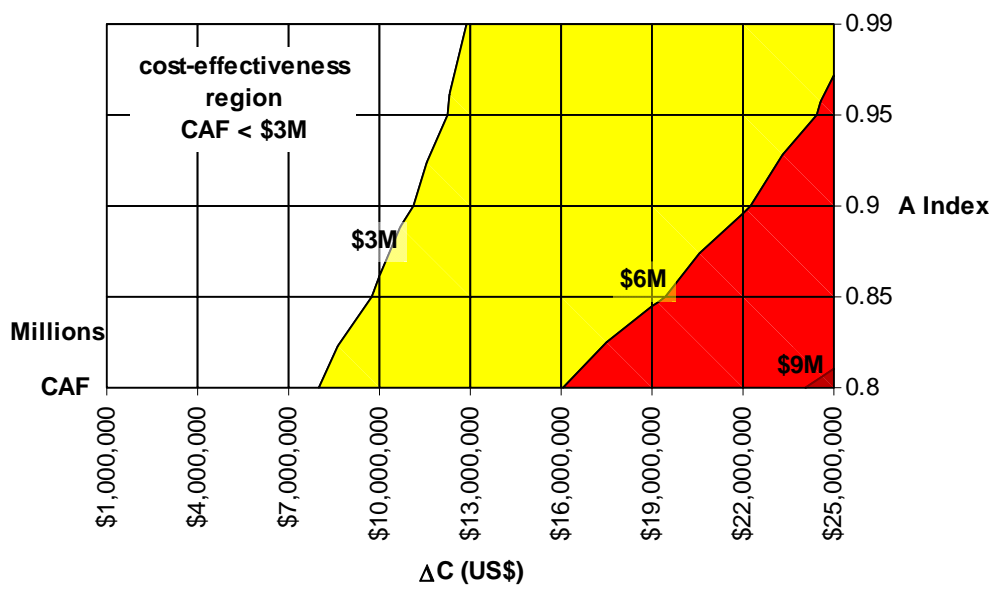

Fig. 10: GCAF sensitivity to Attained index A and cost implications RCO2b: measures improving damage stability and survival time ("stay afloat for longer”) 
Table 1: Number of Incidents and Frequencies

RoPax 1,000 GRT and above (Worldwide, 1994 - 2004)

\begin{tabular}{|l|c|c|c|c|c|c|}
\hline \multirow{2}{*}{} & \multicolumn{2}{|c|}{ \# Incidents } & \multirow{2}{*}{$\%$ Total } & \multirow{2}{*}{$\%$ Serious } & \multicolumn{2}{c|}{ Frequency (per ship year) } \\
\cline { 2 - 3 } & Total & Serious & & \multicolumn{2}{c|}{ Total } & Serious \\
\hline Collision & 194 & 20 & $18.4 \%$ & $11.0 \%$ & $1.25 \mathrm{E}-02$ & $1.29 \mathrm{E}-03$ \\
\hline Contact & 193 & 21 & $18.3 \%$ & $11.6 \%$ & $1.25 \mathrm{E}-02$ & $1.36 \mathrm{E}-03$ \\
\hline Fire/Explosion & 128 & 50 & $12.2 \%$ & $27.6 \%$ & $8.28 \mathrm{E}-03$ & $3.23 \mathrm{E}-03$ \\
\hline Wrecked/Stranded & 148 & 47 & $14.1 \%$ & $26.0 \%$ & $9.57 \mathrm{E}-03$ & $3.04 \mathrm{E}-03$ \\
\hline Hull Damage & 35 & 7 & $3.3 \%$ & $3.9 \%$ & $2.26 \mathrm{E}-03$ & $4.53 \mathrm{E}-04$ \\
\hline Foundered & 2 & 2 & $0.2 \%$ & $1.1 \%$ & $1.29 \mathrm{E}-04$ & $1.29 \mathrm{E}-04$ \\
\hline $\begin{array}{l}\text { Machinery } \\
\text { damage/failure }\end{array}$ & 289 & 31 & $27.5 \%$ & $17.1 \%$ & $2.87 \mathrm{E}-02$ & $2.00 \mathrm{E}-03$ \\
\hline Miscellaneous & 63 & 3 & $6.0 \%$ & $1.7 \%$ & $4.07 \mathrm{E}-03$ & $1.94 \mathrm{E}-04$ \\
\hline TOTAL & $\mathbf{1 , 0 5 2}$ & $\mathbf{1 8 1}$ & $\mathbf{1 0 0 . 0} \%$ & $\mathbf{1 0 0 . 0} \%$ & $\mathbf{6 . 8 0 E}-\mathbf{0 2}$ & $\mathbf{1 . 1 7 E}-\mathbf{0 2}$ \\
\hline
\end{tabular}

Notes: Data as provided and classified within the LMIU casualty database; Fleet-at-risk is 15,468 ship-years for the period 1994 - 2004 as provided by the LRFP world fleet statistics. 
Table 2: Summary Risk Calculations (Risk Model)

\begin{tabular}{|l|c|c|c|c|c|c|}
\hline & $\begin{array}{c}\text { Frequency } \\
\text { (per ship year) }\end{array}$ & $\begin{array}{c}\text { Frequency } \\
\mathbf{( \% )}\end{array}$ & $\begin{array}{c}\text { Individual } \\
\text { Risk } \\
\text { (per year) }\end{array}$ & $\begin{array}{c}\text { PLL } \\
\text { (per ship year) }\end{array}$ & $\begin{array}{c}\text { PLL } \\
\text { (\%) }\end{array}$ & $\begin{array}{c}\text { Fatalities } \\
\text { (per year) }\end{array}$ \\
\hline Collision & $1.25 \mathrm{E}-02$ & $28 \%$ & $2.75 \mathrm{E}-05$ & $2.34 \mathrm{E}-02$ & $11 \%$ & 31 \\
\hline Grounding & $9.57 \mathrm{E}-03$ & $21 \%$ & $3.02 \mathrm{E}-05$ & $2.57 \mathrm{E}-02$ & $12 \%$ & 23 \\
\hline Impact & $1.25 \mathrm{E}-02$ & $28 \%$ & $1.63 \mathrm{E}-06$ & $1.39 \mathrm{E}-03$ & $1 \%$ & 2 \\
\hline Flooding & $2.39 \mathrm{E}-03$ & $5 \%$ & $1.31 \mathrm{E}-04$ & $1.12 \mathrm{E}-01$ & $50 \%$ & 148 \\
\hline Fire & $8.28 \mathrm{E}-03$ & $18 \%$ & $7.00 \mathrm{E}-05$ & $5.95 \mathrm{E}-02$ & $27 \%$ & 79 \\
\hline TOTAL & $\mathbf{4 . 5 2 E - 0 2}$ & $\mathbf{1 0 0} \%$ & $\mathbf{2 . 6 1 E - 0 4}$ & $\mathbf{2 . 2 2 E - 0 1}$ & $\mathbf{1 0 0 \%}$ & $\mathbf{2 8 2}$ \\
\hline
\end{tabular}

Note: Groundings are incidents classified by LMIU as "wrecked/stranded”; Impacts are incidents classified by LMIU as “contact”; Other Flooding includes incidents classified by LMIU as "hull damage” and "foundered”. 
Table 3: Impact of RCO2a (Index A=0.90 Case) on the Risk Model

\begin{tabular}{|l|l|c|c|c|}
\hline \multirow{2}{*}{$\begin{array}{l}\text { Accident } \\
\text { Category }\end{array}$} & \multirow{2}{*}{ ET level 3 } & \multicolumn{2}{|c|}{ ET branch probability } & \multirow{2}{*}{ Enhanced } \\
\cline { 3 - 5 } & & basis & $\begin{array}{c}\text { Enge } \\
\text { by RCO2a }\end{array}$ & \\
\hline Collision & Under way/serious/struck ship/flooding/remains afloat & 0.78 & 0.9 & $15 \%$ \\
\hline Grounding & Serious/flood above DB/floats free/remains afloat & 0.75 & 0.9 & $20 \%$ \\
\hline Impact & Serious/flooding/remains afloat & 0.839 & 0.9 & $7 \%$ \\
\hline \multirow{3}{*}{ Flooding } & Wave damage/bow door/remains afloat & 0.4 & 0.9 & $125 \%$ \\
\cline { 2 - 5 } & Wave damage/stern door/remains afloat & 0.6 & 0.9 & $50 \%$ \\
\cline { 2 - 5 } & Wave damage/hull/remains afloat & 0.7 & 0.9 & $29 \%$ \\
\cline { 2 - 5 } & Open doors/bow/remains afloat & 0.8 & 0.9 & $13 \%$ \\
\cline { 2 - 5 } & Open doors/stern/remains afloat & 0.8 & 0.9 & $13 \%$ \\
\cline { 2 - 5 } & Below car deck/remains afloat & 0.9 & 0.9 & $0 \%$ \\
\hline
\end{tabular}


Table 4: Risk Reduction from Improved Damage Stability (RCO2a)

\begin{tabular}{|c|c|c|c|c|c|}
\hline \multicolumn{2}{|c|}{ Index A } & $\begin{array}{c}\text { Total } \\
\text { Ind. Risk } \\
\text { (per year) }\end{array}$ & $\begin{array}{c}\text { Total PLL } \\
\text { (per ship year) }\end{array}$ & $\begin{array}{c}\text { Averted } \\
\text { fatalities } \\
\text { per ship }\end{array}$ & $\begin{array}{c}\text { Total } \Delta R \\
\text { \% of PLL }\end{array}$ \\
\hline 0.78 & basis & $2.61 \mathrm{E}-04$ & $2.22 \mathrm{E}-01$ & - & \\
\hline 0.80 & $3 \%$ & $2.01 \mathrm{E}-04$ & $1.71 \mathrm{E}-01$ & 1.5 & $23 \%$ \\
\hline 0.85 & $9 \%$ & $1.73 \mathrm{E}-04$ & $1.47 \mathrm{E}-01$ & 2.2 & $33 \%$ \\
\hline $\mathbf{0 . 9 0}$ & $\mathbf{1 5 \%}$ & $\mathbf{1 . 4 6 E - 0 4}$ & $\mathbf{1 . 2 4 E - 0 1}$ & $\mathbf{2 . 9}$ & $\mathbf{4 4 \%}$ \\
\hline 0.95 & $22 \%$ & $1.18 \mathrm{E}-04$ & $1.00 \mathrm{E}-01$ & 3.6 & $55 \%$ \\
\hline 0.99 & $28 \%$ & $9.55 \mathrm{E}-05$ & $8.12 \mathrm{E}-02$ & 4.2 & $63 \%$ \\
\hline
\end{tabular}


Table 5: Risk Reduction Breakdown after Improving Damage Stability (RCO2a - Index A=0.90 Case)

\begin{tabular}{|l|c|c|c|c|}
\hline $\begin{array}{c}\text { RCO2a } \\
\mathbf{A = 0 . 9 0}\end{array}$ & $\begin{array}{c}\text { Frequency } \\
\text { (per ship year) }\end{array}$ & $\begin{array}{c}\text { Ind. Risk } \\
\text { (per year) }\end{array}$ & $\begin{array}{c}\text { PLL } \\
\text { (per ship year) }\end{array}$ & $\begin{array}{c}\Delta \text { PLL } \\
\text { (\%) }\end{array}$ \\
\hline Collision & $1.25 \mathrm{E}-02$ & $1.27 \mathrm{E}-05$ & $1.08 \mathrm{E}-02$ & $54 \%$ \\
\hline Grounding & $9.57 \mathrm{E}-03$ & $1.15 \mathrm{E}-05$ & $9.82 \mathrm{E}-03$ & $60 \%$ \\
\hline Impact & $1.25 \mathrm{E}-02$ & $1.01 \mathrm{E}-06$ & $8.62 \mathrm{E}-04$ & $38 \%$ \\
\hline Flooding & $2.39 \mathrm{E}-03$ & $5.04 \mathrm{E}-05$ & $4.28 \mathrm{E}-02$ & $62 \%$ \\
\hline Fire & $8.28 \mathrm{E}-03$ & $7.00 \mathrm{E}-05$ & $5.95 \mathrm{E}-02$ & $0 \%$ \\
\hline TOTAL & $\mathbf{4 . 5 2 E - 0 2}$ & $\mathbf{1 . 4 6 E - 0 4}$ & $\mathbf{1 . 2 4 E - 0 1}$ & $\mathbf{4 4 \%}$ \\
\hline
\end{tabular}


Table 6: Impact of RCO2b (Index $A=0.95$ Case) on the Risk Model

\begin{tabular}{|c|c|c|c|c|}
\hline \multirow{2}{*}{$\begin{array}{l}\text { Accident } \\
\text { Category }\end{array}$} & \multirow[b]{2}{*}{ ET level 3} & \multicolumn{2}{|c|}{ ET branch probability } & \multirow[b]{2}{*}{ change } \\
\hline & & basis & $\begin{array}{r}\text { Enhanced } \\
\text { by RCO2b }\end{array}$ & \\
\hline \multirow{3}{*}{ Collision } & Under way/serious/struck ship/flooding/remains afloat & 0.78 & 0.95 & $22 \%$ \\
\hline & Under way/serious/struck ship/flooding/sinking/slow sinking & 0.5 & 0.95 & $90 \%$ \\
\hline & /striking ship/flooding/remains afloat & 0.88 & 0.95 & $8 \%$ \\
\hline \multirow[t]{2}{*}{ Grounding } & Serious/flood above DB/floats free/remains afloat & 0.75 & 0.95 & $27 \%$ \\
\hline & /slow sinking & 0.085 & 0.048 & \\
\hline \multirow[t]{2}{*}{ Impact } & Serious/flooding/remains afloat & 0.839 & 0.95 & $13 \%$ \\
\hline & /sinking & 0.059 & 0.024 & \\
\hline \multirow[t]{10}{*}{ Flooding } & Wave damage/bow door/remains afloat & 0.4 & 0.95 & $128 \%$ \\
\hline & /slow sinking & 0.1 & 0.05 & \\
\hline & Wave damage/stern door/remains afloat & 0.6 & 0.95 & $58 \%$ \\
\hline & /slow sinking & 0.3 & 0.05 & \\
\hline & Wave damage/hull/remains afloat & 0.7 & 0.95 & $36 \%$ \\
\hline & /slow sinking & 0.2 & 0.05 & \\
\hline & Open doors/bow/remains afloat & 0.8 & 0.95 & $19 \%$ \\
\hline & /slow sinking & 0.1 & 0.05 & \\
\hline & Open doors/stern/remains afloat & 0.8 & 0.95 & $19 \%$ \\
\hline & Below car deck/remains afloat & 0.9 & 0.95 & $6 \%$ \\
\hline
\end{tabular}


Table 7: Risk Reduction from Improved Damage Survivability (RCO2b)

\begin{tabular}{|c|c|c|c|c|c|}
\hline \multicolumn{2}{|c|}{ Index A } & $\begin{array}{c}\text { Total } \\
\text { Ind. Risk } \\
\text { (per year) }\end{array}$ & $\begin{array}{c}\text { Total PLL } \\
\text { (per ship year) }\end{array}$ & $\begin{array}{c}\text { Averted } \\
\text { fatalities } \\
\text { per ship }\end{array}$ & $\begin{array}{c}\text { Total } \Delta R \\
\text { \% of PLL }\end{array}$ \\
\hline 0.78 & basis & $2.61 \mathrm{E}-04$ & $2.22 \mathrm{E}-01$ & - & \\
\hline 0.80 & $3 \%$ & $1.54 \mathrm{E}-04$ & $1.31 \mathrm{E}-01$ & 2.7 & $40 \%$ \\
\hline 0.85 & $9 \%$ & $1.32 \mathrm{E}-04$ & $1.12 \mathrm{E}-01$ & 3.2 & $49 \%$ \\
\hline 0.90 & $15 \%$ & $1.14 \mathrm{E}-04$ & $9.68 \mathrm{E}-02$ & 3.7 & $56 \%$ \\
\hline $\mathbf{0 . 9 5}$ & $\mathbf{2 2 \%}$ & $\mathbf{9 . 9 5 E - 0 5}$ & $\mathbf{8 . 4 7 E - 0 2}$ & $\mathbf{4 . 1}$ & $\mathbf{6 2 \%}$ \\
\hline 0.99 & $28 \%$ & $9.12 \mathrm{E}-05$ & $7.75 \mathrm{E}-02$ & 4.3 & $65 \%$ \\
\hline
\end{tabular}


Table 8: Risk Reduction Breakdown after Improving Damage Survivability (RCO2b - Index A=0.95 Case)

\begin{tabular}{|l|c|c|c|c|}
\hline $\begin{array}{c}\text { RCO 2b } \\
\mathbf{A}=\mathbf{0 . 9 5}\end{array}$ & $\begin{array}{c}\text { Frequency } \\
\text { (per ship year) }\end{array}$ & $\begin{array}{c}\text { Ind Risk } \\
\text { (per year) }\end{array}$ & $\begin{array}{c}\text { PLL } \\
\text { (per ship year) }\end{array}$ & $\begin{array}{c}\Delta \text { PLL } \\
\text { (\%) }\end{array}$ \\
\hline Collision & $1.25 \mathrm{E}-02$ & $2.50 \mathrm{E}-06$ & $2.13 \mathrm{E}-03$ & $91 \%$ \\
\hline Grounding & $9.57 \mathrm{E}-03$ & $1.05 \mathrm{E}-06$ & $9.61 \mathrm{E}-04$ & $96 \%$ \\
\hline Impact & $1.25 \mathrm{E}-02$ & $1.10 \mathrm{E}-07$ & $9.34 \mathrm{E}-05$ & $93 \%$ \\
\hline Flooding & $2.39 \mathrm{E}-03$ & $2.59 \mathrm{E}-05$ & $2.20 \mathrm{E}-02$ & $80 \%$ \\
\hline Fire & $8.28 \mathrm{E}-03$ & $7.00 \mathrm{E}-05$ & $5.95 \mathrm{E}-02$ & $0 \%$ \\
\hline TOTAL & $\mathbf{4 . 5 2 E - 0 2}$ & $\mathbf{9 . 9 5 E - 0 5}$ & $\mathbf{8 . 4 7 E - 0 2}$ & $\mathbf{6 2 \%}$ \\
\hline
\end{tabular}


Table 9: Reference Ship for Evaluation of RCOs

\begin{tabular}{|l|c|}
\hline Parameters & Value \\
\hline Gross Tonnage, GT & 25,000 tons \\
\hline Length overall & $180 \mathrm{~m}$ \\
\hline Breadth & $25 \mathrm{~m}$ \\
\hline LSA Capacity & 1,100 \\
Passengers & 1,000 \\
Crew & 100 \\
\hline No. cabins / 2 capacity & 50 \\
No. cabins / 4 capacity & 225 \\
\hline Total lane metres & $1,900 \mathrm{~m}$ \\
\hline Lightweight & 12,000 tons \\
\hline
\end{tabular}


Table 10: Reference Vessel Operational Profile

\begin{tabular}{|l|l|c|c|c|}
\hline \multirow{4}{*}{ annual number of trips } & season & $\begin{array}{c}\text { Low } \\
\text { (winter) }\end{array}$ & $\begin{array}{c}\text { Middle } \\
\text { (spring / autumn) }\end{array}$ & $\begin{array}{c}\text { High } \\
\text { (summer) }\end{array}$ \\
\cline { 2 - 5 } & No. service days & 89 & 178 & 89 \\
\cline { 2 - 5 } & Return trips / day (daily frq) & 1 & 1 & 1 \\
\cline { 2 - 5 } & Return trips per year & 89 & 178 & 89 \\
\cline { 2 - 5 } & Annual breakdown & $25 \%$ & $50 \%$ & $25 \%$ \\
\hline \multirow{5}{*}{ pax / vehicle distribution } & cars & 90 & 150 & 301 \\
\cline { 2 - 5 } & bus & 5 & 8 & 3 \\
\cline { 2 - 5 } & lorries & 80 & 60 & 7 \\
\cline { 2 - 5 } & trailer & 100 & 90 & 40 \\
\hline & lane metres used & 1885 & 1845 & 1454 \\
\cline { 2 - 5 } & lane metres usage (\% of max) & $99.2 \%$ & $97.1 \%$ & $76.5 \%$ \\
\cline { 2 - 5 } & Pax (car\&bus) / trip & 420 & 690 & 993 \\
\cline { 2 - 5 } & Pax (drivers) / trip & 80 & 60 & 7 \\
\cline { 2 - 5 } & Pax total / trip & 500 & 750 & 1000 \\
\cline { 2 - 5 } & Level of service & $50 \%$ & $75 \%$ & $100 \%$ \\
\hline
\end{tabular}




\section{Table 11: Unit Cost Data}

\begin{tabular}{|l|l|c|l|}
\hline pertaining to & item & value & units \\
\hline design / construction & consultant hourly rate & 90 & EUR / hour \\
\cline { 2 - 4 } & price of steel work per hour (EU) & 6,000 & EUR / ton \\
\cline { 2 - 4 } & yard cost rate & 20 & EUR / hour \\
\hline tickets prices & pax & 37.4 & EUR / person / trip \\
\cline { 2 - 4 } & Car (3 pax / 4 m) & 52 & EUR / vehicle / trip \\
\cline { 2 - 4 } & Bus (30 pax / 15 m) & 196 & EUR / vehicle / trip \\
\cline { 2 - 4 } & Lorry (1 pax / 15 m) & 196 & EUR / vehicle / trip \\
\cline { 2 - 4 } & Trailer (2.5 m) & 33 & EUR / vehicle / trip \\
\hline onboard sales & car / bus pax & 5 & EUR / person / trip \\
\cline { 2 - 4 } & lorry driver & 5 & EUR / person / trip \\
\hline operational cost & fuel & 280 & EUR / ton \\
\cline { 2 - 4 } & crew wages & & \\
\hline
\end{tabular}


Table 12: Reference Cost / Earning Profile for the Calculation of Marginal Costs

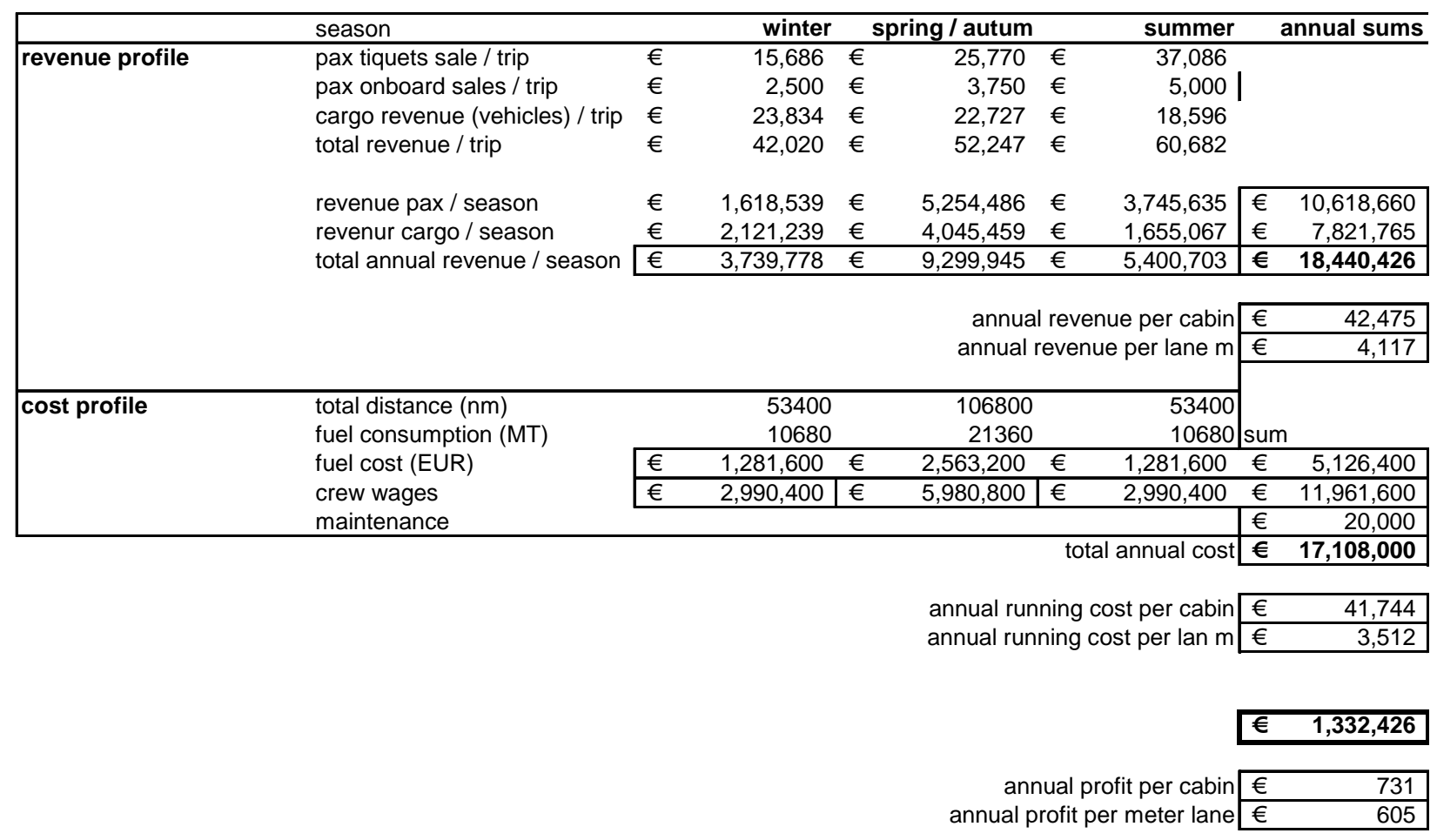


Table 13: Indicative Order of Magnitude of Marginal Costs $\Delta \mathrm{C}$ associated with RCO2a

\begin{tabular}{|c|c|}
\hline \multicolumn{2}{|c|}{$\operatorname{RCO} 2 \mathrm{a}(\mathrm{A}=\mathbf{0 . 9 5})$} \\
\hline stakeholder & item \\
\hline owner & additional tons of steel (1\% lightweight) \\
\hline builder + yard & additional hours of design work \\
\hline operator & Reduced lane metres \\
\hline operator & Reduced cabins \\
\hline stakeholder & item \\
\hline owner & $\begin{array}{l}\text { increased design costs } \\
\text { (fixed price) }\end{array}$ \\
\hline builder & $\begin{array}{l}\text { increased design costs } \\
\text { (fixed price) }\end{array}$ \\
\hline owner & $\begin{array}{l}\text { increased construction costs } \\
\text { (due to added weight) }\end{array}$ \\
\hline builder & $\begin{array}{l}\text { increased construction costs } \\
\text { (commissioning) }\end{array}$ \\
\hline stakeholder & item \\
\hline owner & $\begin{array}{l}\text { cost of reduced capacity } \\
\text { (car deck space) }\end{array}$ \\
\hline owner & cost of possible increased maintenance \\
\hline owner & $\begin{array}{l}\text { cost of reduced capacity } \\
\text { (accommodation spaces) }\end{array}$ \\
\hline
\end{tabular}

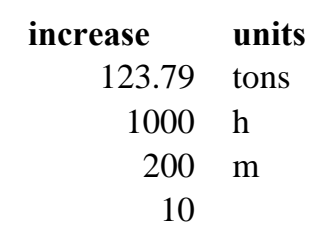

$\begin{array}{llll}\text { initial (capital) cost } & € & 792,759 \\ € \quad 15,000 & \\ € & 15,000 \\ € & 742,759 \\ € & 20,000\end{array}$

annual (running) cost $€ \quad 129,327$

$€ \quad 121,015$

$€ \quad 1,000$

$€ \quad 7,311$

\$ $3,075,531$ 


\section{Table 14: Indicative Order of Magnitude of Marginal Costs $\Delta \mathrm{C}$ associated with RCO2b}

\begin{tabular}{|c|c|c|c|c|c|c|}
\hline \multicolumn{7}{|c|}{$\operatorname{RCO} 2 b(A=0.95)$} \\
\hline stakeholder & item & \multicolumn{2}{|c|}{ increase } & \multicolumn{3}{|l|}{ units } \\
\hline owner & additional tons of steel ( $5 \%$ lightweight) & & 618.97 & tons & & \\
\hline builder + yard & additional hours of design work & & 5000 & $\mathrm{~h}$ & & \\
\hline operator & Reduced lane metres & & 50 & $\mathrm{~m}$ & & \\
\hline operator & Reduced cabins & & 10 & & & \\
\hline stakeholder & item & \multicolumn{3}{|c|}{ initial (capital) cost } & $€$ & $3,843,793$ \\
\hline owner & $\begin{array}{l}\text { increased design costs } \\
\text { (fixed price) }\end{array}$ & \multicolumn{3}{|c|}{$€ \quad 15,000$} & & \\
\hline builder & $\begin{array}{l}\text { increased design costs } \\
\text { (fixed price) }\end{array}$ & \multicolumn{3}{|c|}{$€ \quad 15,000$} & & \\
\hline owner & $\begin{array}{l}\text { increased construction costs } \\
\text { (due to added weight) }\end{array}$ & \multicolumn{3}{|c|}{$€ 3,713,793$} & & \\
\hline builder & $\begin{array}{l}\text { increased construction costs } \\
\text { (commissioning) }\end{array}$ & $€$ & \multicolumn{2}{|l|}{100,000} & & \\
\hline stakeholder & item & \multicolumn{3}{|c|}{ annual (runing) cost } & $€$ & 38,565 \\
\hline owner & $\begin{array}{l}\text { cost of reduced capacity } \\
\text { (car deck space) }\end{array}$ & $€$ & 30,254 & & & \\
\hline owner & cost of possible increased maintenance & $€$ & 1,000 & & & \\
\hline owner & $\begin{array}{l}\text { cost of reduced capacity } \\
\text { (accommodation spaces) }\end{array}$ & $€$ & 7,311 & & & \\
\hline Increase in co & NPV & $\$$ & $\mathbf{5 , 8 5 0 , 9 5 2}$ & & $€$ & $4,277,950$ \\
\hline
\end{tabular}

